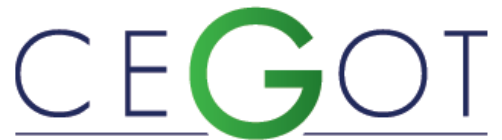

Centro de Estudos de Geografia e Ordenamento do Território
COTA, THALITTA

Universidade Federal de Rondônia (UNIR), Departamento de Engenharia Ambiental (DEA)

Rua Senador Artur Cezar Rios, 1313 bairro Colina Park II, 76906-780, Ji-

Paraná, Brasil

thalitta.cota@gmail.com

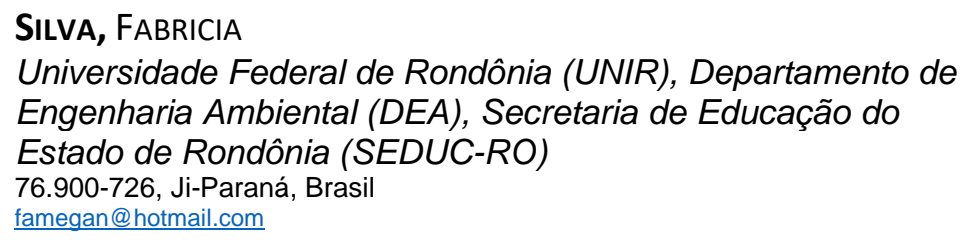

\section{GonçALVES, ANA}

Universidade Federal de Rondônia (UNIR), Departamento de Engenharia Ambiental (DEA), Instituto Federal de Rondônia (IFRO)

76.900-726, Ji-Paraná, Brasil ana.goncalves@ifro.edu.br

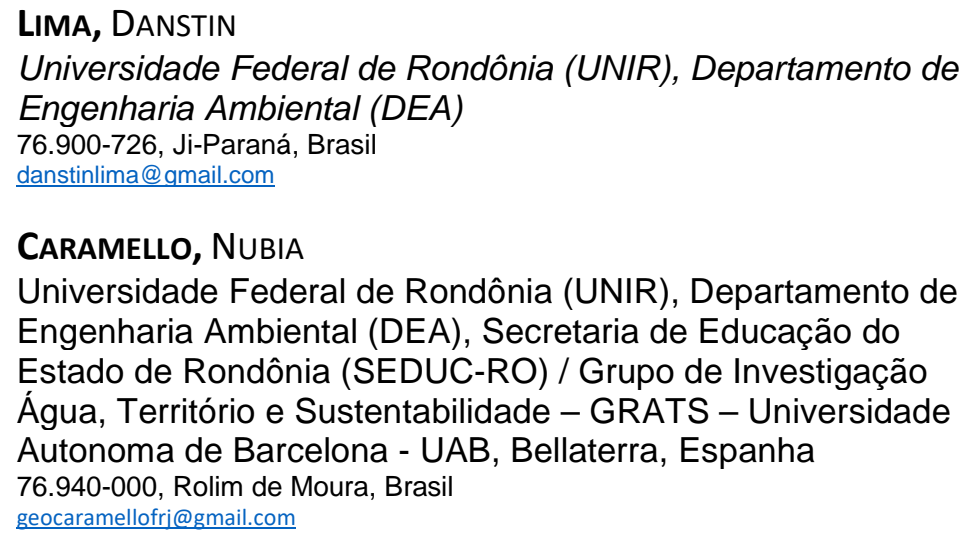

Caramello, Nubia

Universidade Federal de Rondônia (UNIR), Departamento de Engenharia Ambiental (DEA), Secretaria de Educação do Estado de Rondônia (SEDUC-RO) / Grupo de Investigação Água, Território e Sustentabilidade - GRATS - Universidade Autonoma de Barcelona - UAB, Bellaterra, Espanha 76.940-000, Rolim de Moura, Brasil geocaramellofri@gmail.com

\title{
Indicadores socioambientais como instrumento de gestão de território fluvial: comunidade de Rolim de Moura do Guaporé-RO
}

Socio-environmental indicators as tools for river land management: Rolim de Moura do Guaporé-RO community

Referência: Cota, Thalitta et al. (2019). Indicadores socioambientais como instrumento de gestão de território fluvial: comunidade de Rolim de Moura do Guaporé-RO. Revista de Geografia e Ordenamento do Território (GOT), n. ${ }^{\circ} 17$ (junho). Centro de Estudos de Geografia e Ordenamento do Território, p. 29-54, dx.doi.org/10.17127/got/2019.17.002

\section{RESUMO}

Objetivo deste estudo é mapear e analisar os indicadores de sustentabilidade socioambientais na Comunidade de Rolim de Moura do Guaporé. Por meio de oficina de diálogos socioambientais, aplicação de questionário e visita técnica, construímos a matriz (PEIR) dos Indicadores de Sustentabilidade pela percepção da comunidade com base no proposto pela Organização de Cooperação e Desenvolvimento Econômico. Foram mapeados 48 indicadores, 17 das Pressões exercidas no meio ambiente, 17 de Estado e 14 de 
Resposta. Os indicadores de Impactos foram identificados 15 pela análise do atual estado do meio ambiente. Diante dos indicadores, sugere mudanças nas atuais políticas públicas aplicadas em comunidades tradicionais, promovendo uma gestão territorial participativa com auxílio da educação ambiental, contribuição técnica, visando minimizar as problemáticas ambientais.

Palavras-chave: Comunidade Tradicional. Indicadores de sustentabilidade. PEIR. Políticas Públicas.

\section{ABSTRACT}

The goals of the current study were to map and to analyze the social and environmental sustainability indicators in the Rolim de Moura of Guaporé Community. Through socioenvironmental dialogues workshops, questionnaire applications and technical visits in the community, we constructed a Sustainability Indicators Matrix Pressure-State-Response (PSIR) through the community perception considering method proposed by the Organization for Economic Cooperation and Development. A total of 48 indicators were mapped (17 classified such as environmental pressures, 17 of state and 14 of response). In addition, 15 impact indicators were identified by the analysis of the current state of the environment. This research suggests of change the current public policies applied in traditional communities, promoting participatory territorial management with the aid of environmental education, technical contribution, aiming to minimize environmental problems.

Keywords: Traditional Community. Indicators of sustainability. PSIR. Public policy

\section{Introdução}

O crescimento exponencial e desordenado da população mundial tem gerado debates, não somente com relação aos processos de urbanização, mas também aos aspectos territoriais no contexto geral e o processo de governança diante desse desafio. O quesito meio ambiente está diretamente relacionado à preservação e apropriação dos recursos naturais, assim como à qualidade de vida do ser humano. Esses aspectos vêm tornando a discussão da problemática ambiental e do processo de desenvolvimento "sustentável" cada vez mais essencial para a manutenção do diálogo nas tomadas de decisões.

Com as transformações no meio ambiente, a fim de subsidiar as necessidades humanas, foram ocorrendo diversos impactos que interferem diretamente na qualidade de vida das pessoas, sendo necessário analisá-los tanto em seu aspecto quantitativo como qualitativo. Como Veiga cita "Uma coisa é medir desempenho econômico, outra é medir qualidade de 
vida (ou bem-estar), e uma terceira é medir a sustentabilidade do desenvolvimento." (Veiga, 2010, p.46).

Uma das maneiras de mensurar o uso dos recursos naturais identificando seus impactos e o que a sociedade tem feito para minimizá-los, se dá por meio dos indicadores de sustentabilidade. Em uma de suas obras Siche et al. (2007) afirma que os indicadores funcionam como um sinal para demonstrar a situação do sistema avaliado, visto que são valores estáticos, revelando a real situação da área estudada.

Neste aspecto, o uso de indicadores como ferramenta de gestão pode facilitar e agregar argumentos nas tomadas de decisões em distintas escalas. Apesar de ter surgido há anos, quando a tecnologia ainda era insuficiente para subsidiar o ser humano na identificação dos problemas ambientais, os indicadores continuam exercendo papel essencial diante da realidade de uma sociedade consumista que, com suas ações, poderá gerar o esgotamento dos recursos naturais. A sua aplicabilidade ainda é desconhecida por um significativo número de gestores, agravando ainda mais em cidades de pequeno porte no interior da região Amazônica com impacto direto em comunidades tradicionais, seja pela ausência de técnicos habilitados, escassez de recursos, ou outras prioridades. Como afirma Veiga (2010), o debate científico sobre indicadores de sustentabilidade foi desencadeado há quase 40 anos por um trabalho que continua amplamente visto como "seminal".

Visando contribuir no debate dos indicadores de desenvolvimento sustentável, entre esses, os indicadores ambientais, a Organização de Cooperação e Desenvolvimento Econômico (OCDE) em seu corpo central, com intuito de acompanhar os progressos alcançados em matéria de meio ambiente e dos fatores em causa, comumente utiliza os indicadores, com objetivo de acompanhar, zelar e integrar a variável ambiental pelos diversos setores da sociedade, política e economia, estabelecendo uma mão única de comunicação, e assim, possibilitando através do uso da metodologia Pressão-Estado-Resposta (PER) um quadro comum harmonizado (OCDE, 2002). Tal metodologia adaptada pelo Programa das Nações Unidas para o Meio Ambiente (PNUMA), vem ganhando destaque no viés científico, buscando compreender a real situação de determinado local e como as forças de pressão estão agindo sobre os mesmos, apontando quais impactos estão sofrendo, e quais respostas podem direcionar as tomadas de decisões. 
De acordo com Vaz e Silveira (2014) a utilização dos indicadores ambientais, em consonância com a metodologia PEIR, indica o nível de qualidade da área de estudo. Esse modelo empregado busca analisar as pressões exercidas no meio e suas consequências, respondendo aos questionamentos: o que está acontecendo com o ambiente (Estado); por que isso ocorre (Pressão); qual é o impacto causado pelo estado do meio ambiente (Impacto) e o que a sociedade está fazendo a respeito (Resposta) (Carvalho e Barcellos, 2010).

O uso de indicadores ambientais como metodologia de contextualização do desenvolvimento sustentável no Brasil é recente, o Instituto Brasileiro de Geografia e Estatística (IBGE) utilizou a abordagem conceitual do modelo PEIR, após a Conferência das Nações Unidas sobre Meio Ambiente e Desenvolvimento, realizada no Rio de Janeiro em 1992, nas versões de Indicadores de Desenvolvimento Sustentável de 2002, 2004, 2008, 2010, 2012 e 2015 (IBGE, 2019a) sendo observado alguns esforços institucionais na utilização desse modelo. A utilização dos indicadores permite entender os fatores determinantes das características que influenciam o meio ambiente em qualquer escala territorial. Assim, ao analisar o estado ambiente, é preciso compreender dois elementos: os recursos naturais (água, ar, solo, biodiversidade) e o ecossistema, a fim de entender o modo que um território se conecta com os recursos naturais (PNUMA, 2004).

Buscando entender quais elementos respondem a problemática socioambiental em um território fluvial, esse artigo tem como objetivo mapear e analisar os indicadores de sustentabilidade socioambientais da Comunidade de Rolim de Moura do Guaporé, com intuito de contribuir na identificação dos principais problemas enfrentados na ilha sob a ótica perceptiva da comunidade, fornecendo subsídios para a gestão territorial e tomadas de decisões da população e do poder público. 


\section{Material e métodos}

\section{1. Área de estudo}

O estudo foi realizado na Comunidade de Rolim de Moura do Guaporé, território de 1.500 hectares, distrito pertencente ao município de Alta Floresta d'Oeste - Rondônia. Inserida num contexto fluvial, a comunidade está localizada na Bacia Hidrográfica do Rio Mequéns, afluente do Rio Guaporé, no entorno do Parque Estadual de Corumbiara, divisa internacional com a República Boliviana. De acordo com os moradores, a ilha é composta por uma população de aproximadamente 1.000 a 1.300 habitantes (Dinâmica demográfica ocorre principalmente no período de turismo de pesca), sua estrutura urbana situa-se na confluência entre os rios Mequéns e Guaporé (Figura 1).

O acesso à comunidade se dá percorrendo aproximadamente $165 \mathrm{Km}$ a partir do município de Alta Floresta D'oeste - RO por uma estrada de cascalho, a RO 135, e com mais $15 \mathrm{Km}$ em uma viagem fluvial pelo rio Mequéns (SEDAM, 2009) com duração de 2 a 3 horas dependendo do período do ano.

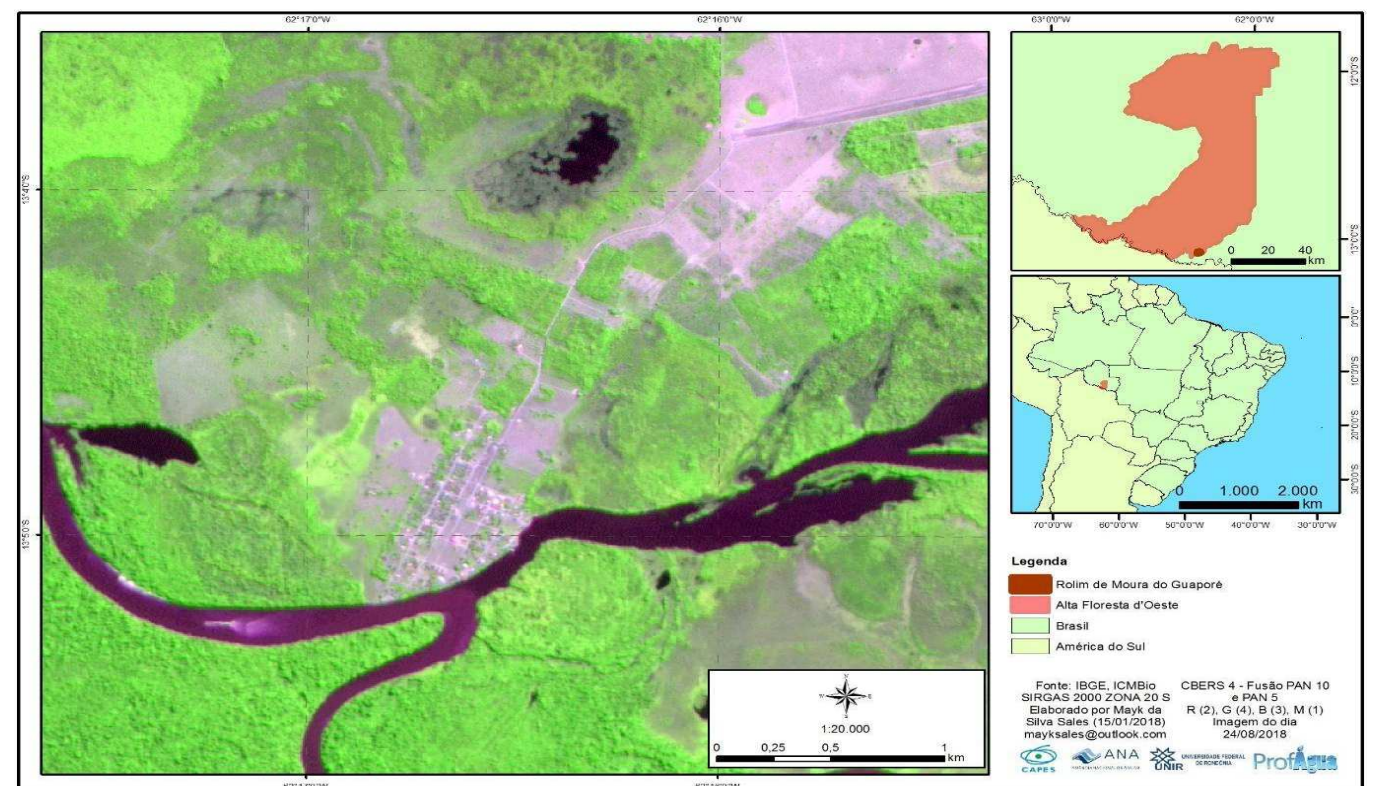

Figura 1.Mapa de localização do Distrito de Rolim de Moura do Guaporé. Fonte: Elaborado por Mayk da Silva Sales com base em IBGE (2019b), para o presente estudo.

O distrito de Rolim de Moura do Guaporé, popularmente conhecido como Porto Rolim, foi certificado em 20 de janeiro de 2006 pelo Processo no 01420.002954/2005-91 como remanescente de quilombolas (BRASIL, 2017). Contudo a comunidade é composta por uma 
população multiétnica, formada por comunidades quilombolas, indígenas, ribeirinhos, brancos e imigrantes bolivianos. Em um cenário de múltiplos olhares, a comunidade de Rolim de Moura do Guaporé interpola características únicas, que retratam a vivência nesse local.

\subsection{Coleta de dados}

As coletas de dados para mapear e identificar os indicadores socioambientais na comunidade de Rolim de Moura do Guaporé, foram realizadas nos dias 15 e 16 de novembro de 2018 , distribuídas em três etapas.

1a etapa: Desenvolvimento de oficina de diálogos que, por meio dos olhares multidisciplinares da equipe envolvida no estudo, foi possível observar os indicadores socioambientais presentes na comunidade através de exercícios e dinâmicas com abordagem da metodologia Pressão-Estado-Impacto-Resposta (PEIR), onde os atores identificaram, apresentaram e discutiram as pressões existentes na comunidade.

$\mathrm{Na}$ oficina a comunidade foi dividida em grupos para a aplicação da metodologia PEIR, e com apoio de membros da equipe de pesquisa, pode-se extrair pela visão dos moradores, os indicadores socioambientais. A abordagem do modelo PEIR foi realizada pelos aspectos: "O que está acontecendo com o meio ambiente?" (PRESSÃO), “Por que isto está acontecendo?" (ESTADO), "Qual o impacto causado pelo estado do meio ambiente?" (IMPACTO), "O que estamos fazendo a respeito?", "O que acontecerá se não agirmos agora? " (RESPOSTA) apresentando os resultados e discutindo entre os grupos, com voz e olhar dos moradores da comunidade Figura 2. 

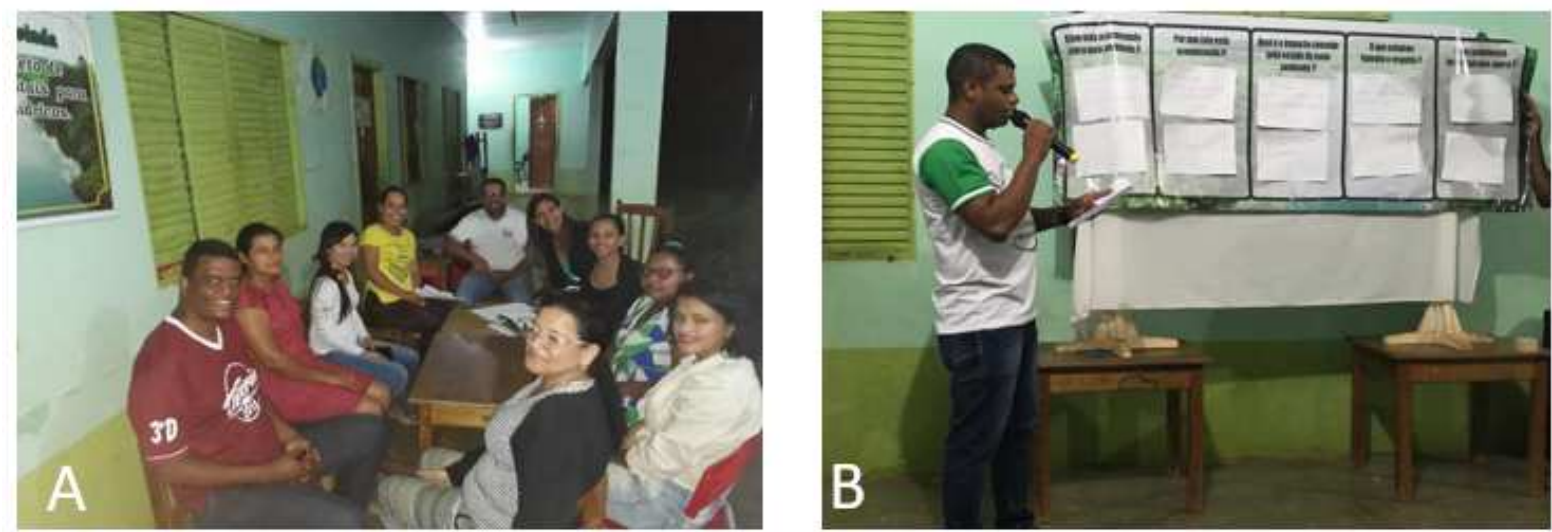

Figura 2. Oficina de diálogo na Comunidade de Rolim de Moura do Guaporé. A) grupo de debate entre os moradores da comunidade e equipe da pesquisa; B) Apresentação dos resultados entre os grupos. Fonte: Os autores (banco de dados da pesquisa, novembro de 2018).

2a etapa: Foi realizada aplicação de questionários com os moradores da comunidade, a fim de colher informações que contemplam a rede de dados do IBGE-Cidades (Figura 3) permitindo uma interpretação mais realista da área de estudo. Foram mensurados dados de Densidade demográfica (número de moradores/área territorial da ilha); Rendimento mensal per capita/familiar; Fonte de renda (setores da economia); Fonte de acesso à água; Moradores por residência; Mobilidade; Destino resíduo líquido e sólido; Tipo de alimentação.
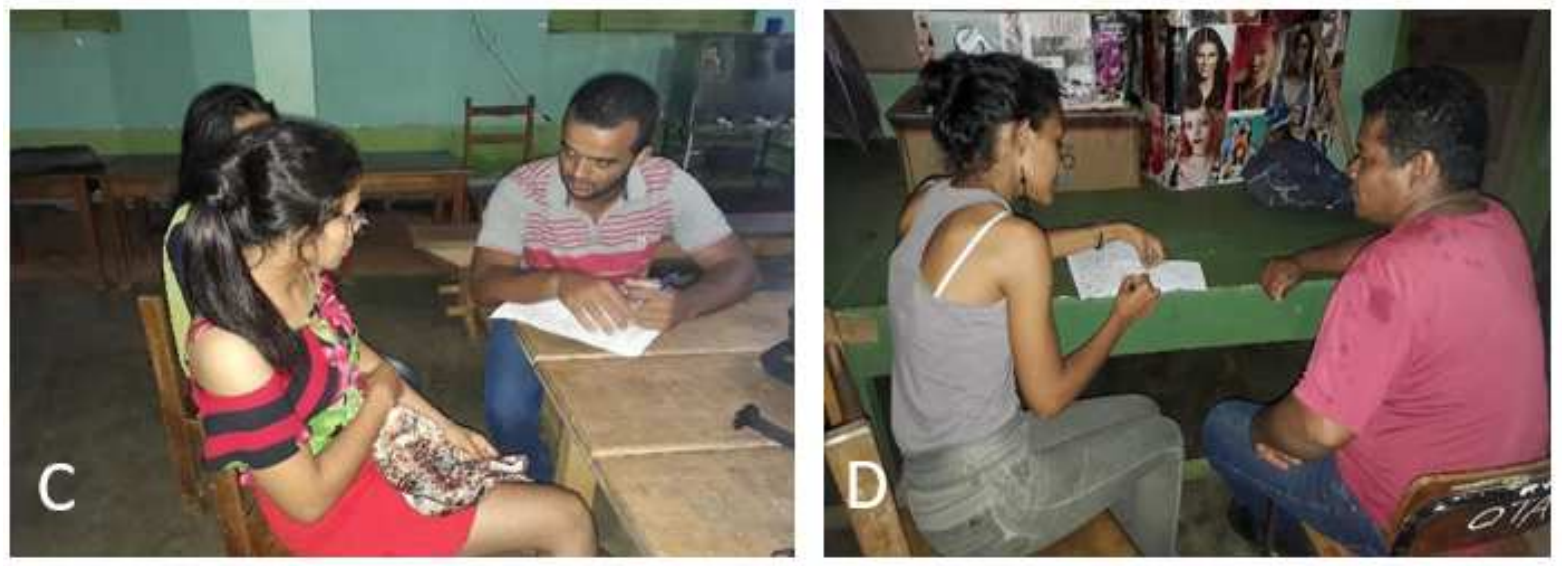

Figura 3. Aplicação de questionário com os moradores da comunidade C) e D).

Fonte: Os autores (banco de dados da pesquisa, novembro de 2018).

3a etapa: Foram realizadas, com as lideranças da comunidade, visitas técnicas nos locais pontuados como mais importantes e/ou críticos da ilha (Figura 4). Fundamentado de anotações técnicas e registros fotográficos, foi possível interpretar quais os aspectos 
socioambientais têm sofrido pressões e quais indicadores Pressão, Estado, Impacto e Resposta foram evidenciados.
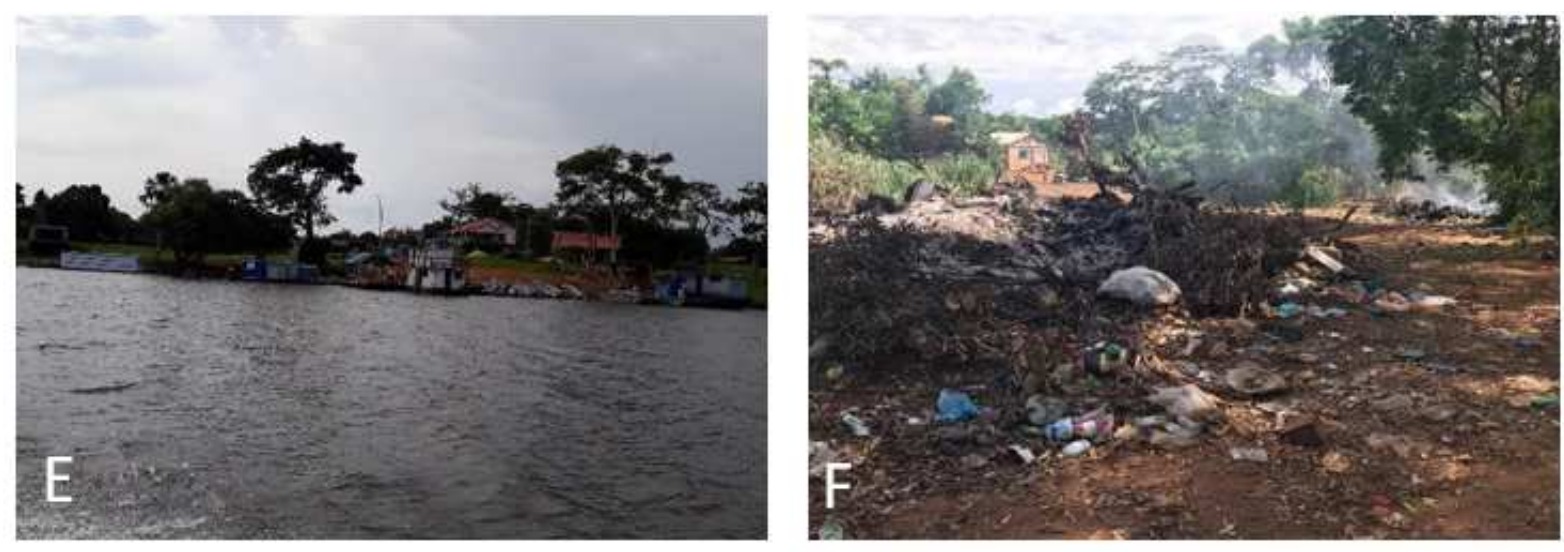

Figura 4. Visita técnica, E) porto de chegada da comunidade e F) lixão a céu aberto da comunidade. Fonte: Os autores (banco de dados da pesquisa, novembro de 2018).

\subsection{Matriz Pressão-Estado-Impacto-Resposta (PEIR)}

A metodologia PEIR é uma ferramenta de construção de indicadores que proporciona uma aplicabilidade de enquadramento conforme a realidade. Ou seja, a utilização do PEIR possibilita uma classificação específica e o posicionamento dos indicadores nas dimensões de Pressão, Estado, Impacto e Resposta (Silva, 2012).

De acordo com o Programa das Nações Unidas para o Meio Ambiente PNUMA (2002), as dimensões da metodologia PEIR são definidas como:

PRESSÃO - força exercida pela atividade humana sobre o meio ambiente, geralmente denominada causas ou vetores de mudança;

ESTADO - condição do meio ambiente que resulta das pressões;

IMPACTOS - efeitos produzidos pelo estado do meio ambiente sobre diferentes aspectos, como os ecossistemas, qualidade de vida humana, economia urbana local;

RESPOSTA - ações coletivas ou individuais que aliviam ou previnem os impactos ambientais negativos, corrigem os danos ao meio ambiente, conservam os recursos naturais ou contribuem para a melhoria da qualidade de vida da população local.

(PNUMA, 2002, p.13).

Essas Pressões podem ser geradas pelas forças econômicas e sociais, tais como o crescimento da população, o consumo ou pobreza e interferem no ambiente determinando a quantidade e qualidade dos recursos naturais disponíveis. Com relação ao Estado, é importante identificar os níveis de qualidade dos recursos naturais e sociais mediante as pressões sofridas no meio ambiente. Desse modo, as pressões exercidas acarretam um 
determinado estado que poderá gerar impactos para a sociedade e ambiente como um todo. Por fim, espera-se que algo seja feito para mitigar ou sanar os impactos gerados no meio, essa é a resposta, fundamental para manter um ambiente ecologicamente equilibrado e sadio suficientemente para suprir as necessidades de todos.

Para a construção da matriz de indicadores, neste estudo foram utilizadas informações colhidas na Comunidade, criando um banco de dados seguindo o modelo da OCDE PressãoEstado-Resposta (PER). Com base nas fontes de referências das entidades nacionais e internacionais, responsáveis pela elaboração dos indicadores disponíveis no Sistema de Indicadores de Desenvolvimento Sustentável (SIDS), onde consta a lista de indicadores para cada aspecto condicionante do desenvolvimento sustentável, considerando a fundamentação de quatro categorias: indicadores ambientais $(A)$, sociais $(S)$, econômicos $(E)$ e institucionais (I) (OCDE, 2000).

Foram mapeados os indicadores das quatros categorias, em seus diversos setores: Ar; Ambiente marinho e Costeiro (adaptado para a área de estudo); Água doce; Solos; Conservação da Natureza; Resíduos; Economia; Energia; Transporte; Turismo; Saúde; Educação; Emprego; Instituições e outros. Considerando seus respectivos tipos: Pressão; Estado e Resposta (OCDE, 2000), correlacionado com o banco de dados obtidos em campo.

Todas as informações foram analisadas a partir da dinâmica de uso e ocupação do solo, a análise do discurso obtido através da percepção da comunidade e as diretrizes da OCDE (2000), proporcionando a construção de três Matriz PEIR: a primeira com indicadores de sustentabilidade aplicados ao Uso e Ocupação do Solo e Demanda Hídrica; a segunda com indicadores de sustentabilidade aplicados ao Ecossistema, Cultura e Economia; e a terceira indicadores de sustentabilidade aplicados ao Saneamento Básico e Resíduos Sólidos.

\section{Resultados e discussões}

Fundamentado que este estudo está integrado a um macro estudo sobre indicadores de sustentabilidade na Comunidade de Rolim de Moura do Guaporé, neste artigo pretende-se apresentar e discutir os indicadores como instrumento para gestão, dividido em áreas de 
atuação, identificados como ponto de partida na gestão socioambiental da comunidade a ser aplicada em um diálogo de gestão de recursos hídricos pela comunidade.

\subsection{Uso e ocupação do solo e demanda hídrica}

Com os dados adquiridos a partir da metodologia apresentada, pode-se identificar o estado em que se encontra a área da comunidade, bem como os impactos gerados pelo reflexo da pressão exercida nesta e quais ações a população vêm desenvolvendo para mitigar os impactos sofridos pela ação antrópica.

A área de estudo, comunidade Rolim de Moura do Guaporé, está geomorfologicamente inserida num território fluvial. Nunes (2016) destaca que, de acordo com o Instituto Brasileiro de Geografia e Estatística (IBGE, 2010), sua população é de aproximadamente 659 habitantes, sendo 401 na área urbana e 258 na área rural, o que representa uma baixa população absoluta se comparada às localidades próximas. Porém, vale ressaltar que a comunidade afirma que esse número ultrapassa os 1000 habitantes.

Proporcionado por um estado do meio onde a população depende econômica e socialmente da água, esta exerce papel fundamental no território. Desta maneira, foi identificado que dos cinco indicadores mapeados em pressão, três estão relacionados diretamente com o acesso e uso da água (Figura 5). Como a área de estudo agrega várias comunidades tradicionais, suas atividades diárias estão integradas aos recursos hídricos como a pesca, a agropecuária, o lazer e o turismo. Além do exposto, várias das preocupações relatadas pela comunidade também estão ligadas à demanda hídrica. 


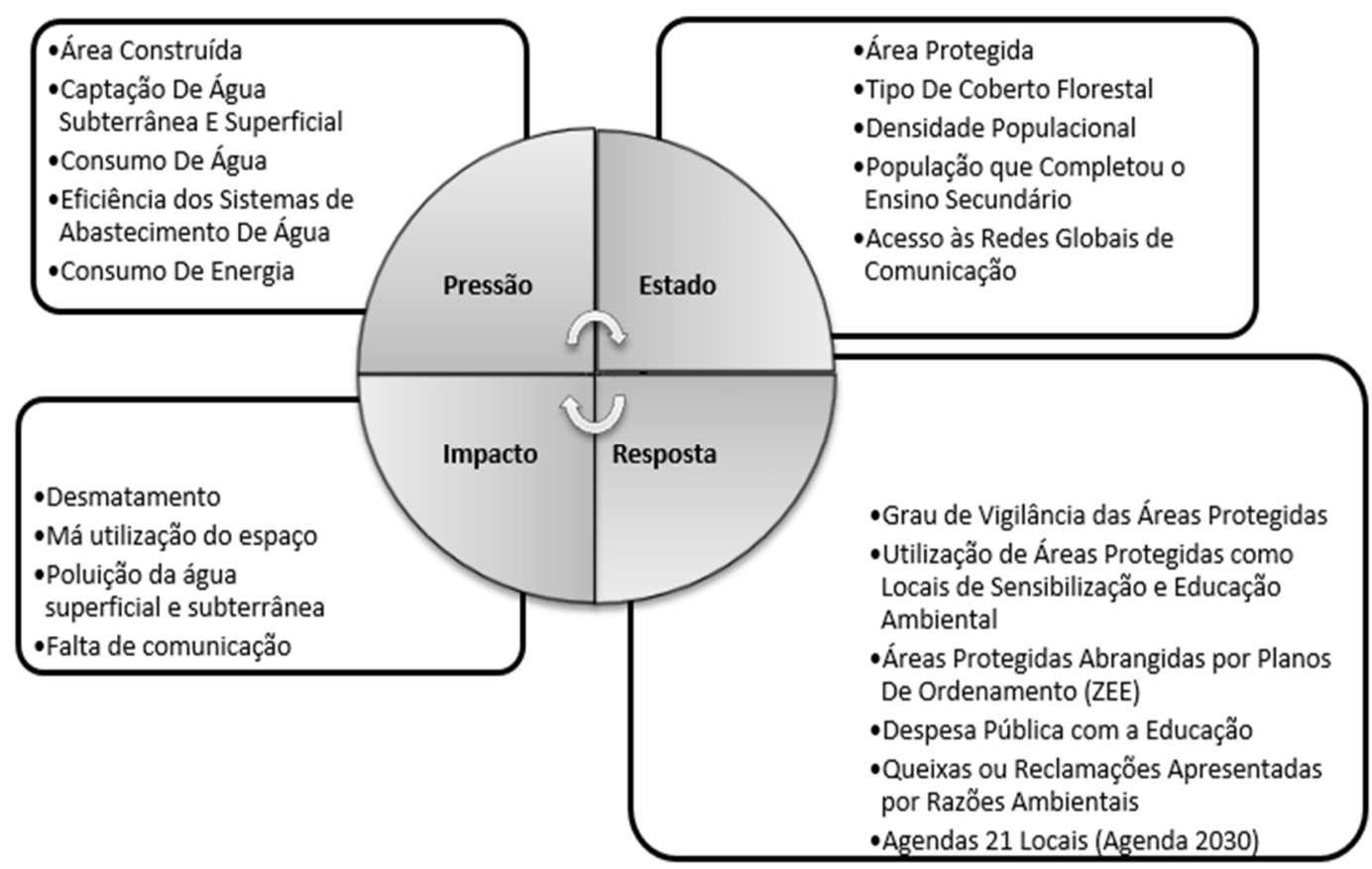

Figura 5. Matriz PEIR de indicadores de sustentabilidade aplicados ao Uso e Ocupação do Solo e Demanda Hídrica. Fonte: organizado pelos autores a partir da pesquisa in loco e diretrizes de indicadores da OCDE (2000).

Por meio do mapeamento da área estudada pode-se identificar que esta apresenta uma densidade demográfica de $43,9 \mathrm{hab} / \mathrm{km}^{2}$, porém, ocupando apenas $4,1 \%$ do total da área territorial, o que não torna o povoado a principal causa dos índices de desmatamento atuais. Ainda que a maior parte da população de Rolim de Moura do Guaporé se encontre na parte urbana do território fluvial, onde as construções são simples e irregulares, algumas sendo utilizadas para comportar a demanda turística, os maiores impactos sobre o solo ocorrem na área rural, onde a concentração populacional é menor.

Como resultado da visita técnica, pode-se perceber que, mesmo na área urbana, há uma boa parte dos terrenos que ainda não foram ocupados, algumas residências são utilizadas para aluguel na temporada do turismo da pesca esportiva e permanecem fechadas no período de proibição da atividade no estado, denominado época do defeso. Porém, como relatado pelos moradores e pela visualização in loco, pode-se perceber que com a ocupação humana, decorrente das colonizações ao longo dos anos trazendo novas dinâmicas de uso como a criação de gado, a ocupação territorial resultou em desmatamento, transformando $40,1 \%$ da área em pastagem e mantendo-se ainda aproximadamente $53,8 \%$ de área em florestas (figura 6). 


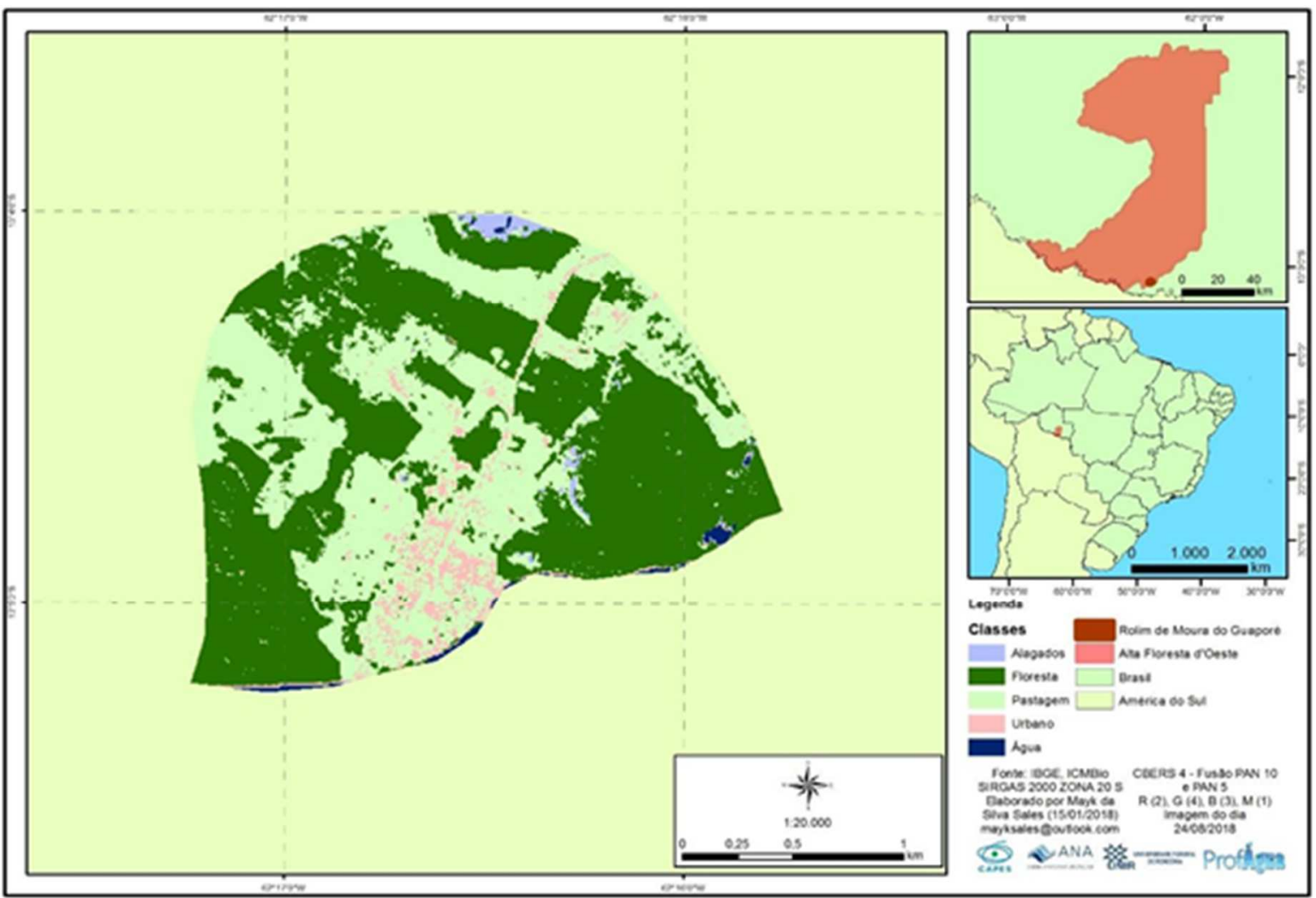

Figura 6. Mapa de uso e ocupação do solo da Comunidade de Rolim de Moura do Guaporé. Fonte: Elaborado por Mayk da Silva Sales com base em dados do IBGE (2019b) e dados coletados em campo, para o presente estudo.

Nesta região a agricultura se apresenta principalmente na forma de subsistência, porém a produção bovina é bem representativa. Segundo dados da Agência de Defesa Sanitária Agrosilvopastoril do Estado de Rondônia (IDARON), na campanha de vacinação de 2018 foram registrados 5.151 cabeças de gado. Boa parte dos alimentos consumidos pela comunidade advém de outras localidades trazidas pelas embarcações. Como não existem grandes lavouras, com uso intensivo de defensivos agrícolas, os impactos gerados por essa atividade no território fluvial não são tão visíveis. Contudo, a produção agropecuária, além de ocasionar a substituição da vegetação nativa pela pastagem, ainda pode acarretar compactação do solo e contaminação dos corpos hídricos.

Rolim de Moura do Guaporé está inserida próximo do Parque Estadual Corumbiara, onde a fiscalização e a preocupação para a preservação de espécies animais e vegetais nativas/endêmicas deveria ser prioridade. Isso muitas vezes não ocorre por parte de visitantes e turistas, gerando reclamações por parte da população que depende dos recursos naturais para sua sobrevivência. Inclusive os moradores relatam que a presença dos integrantes dos órgãos ambientais na região é cada vez menos significativa. 
Por meio de entrevistas e diálogo com os moradores, pode-se perceber que a maior parte da população possui poços, visto que não há rede de abastecimento de água. Estes utilizam a água dos rios que banham a comunidade principalmente para pesca, lazer e balneabilidade. Por ser um território fluvial há abundância hídrica, o que não significa qualidade, haja visto que a rede de saneamento é inexistente. Além disso, vale salientar que não há um controle de qualidade de água na comunidade, onde poços estão muito próximos das fossas sépticas (negras) gerando possivelmente altos índices de contaminação e acarretando problemas de saúde à população.

No que se refere à educação, na área de estudo possui uma escola municipal de ensino infantil e fundamental denominada Ana Nery, que oferta também o ensino médio por meio de extensão da Escola Ezequiel Ramim, de Alta Floresta d'Oeste (sede municipal), com a implantação da mediação tecnológica. Durante a pesquisa o espaço da escola foi cedido para o desenvolvimento de oficinas contando com a participação dos funcionários, alunos e comunidade em geral. A escola possui uma estrutura simples e um número pequeno de alunos (118 alunos da rede municipal e 17 da rede estadual no ano de 2018, segundo a direção da escola), compatível com a realidade da comunidade. Em decorrência da ausência de uma continuidade da vida acadêmica, ou pela falta de emprego, algumas pessoas deixam o distrito indo em direção de núcleos urbanos mais desenvolvidos e com mais subsídios, buscando melhores condições de vida.

A escola acaba por se tornar uma referência para a comunidade, efetivando não somente o papel intelectual como também o de intermediador de gestão territorial. Apesar da falta de acesso às redes de telecomunicações, visto que a internet não é algo de acesso a todos, pois poucas residências a possuem e o sinal de telefonia não funciona, a população demonstra senso crítico e se apresenta ativa na busca de seus direitos e de um equilíbrio ambiental. Muitos habitantes não completaram o ensino básico (Figura 7), mas, baseada em sua vivência, demonstram muita sabedoria no que condiz ao uso dos recursos naturais, visto que a manutenção destes é de suma importância para a sua sobrevivência. 


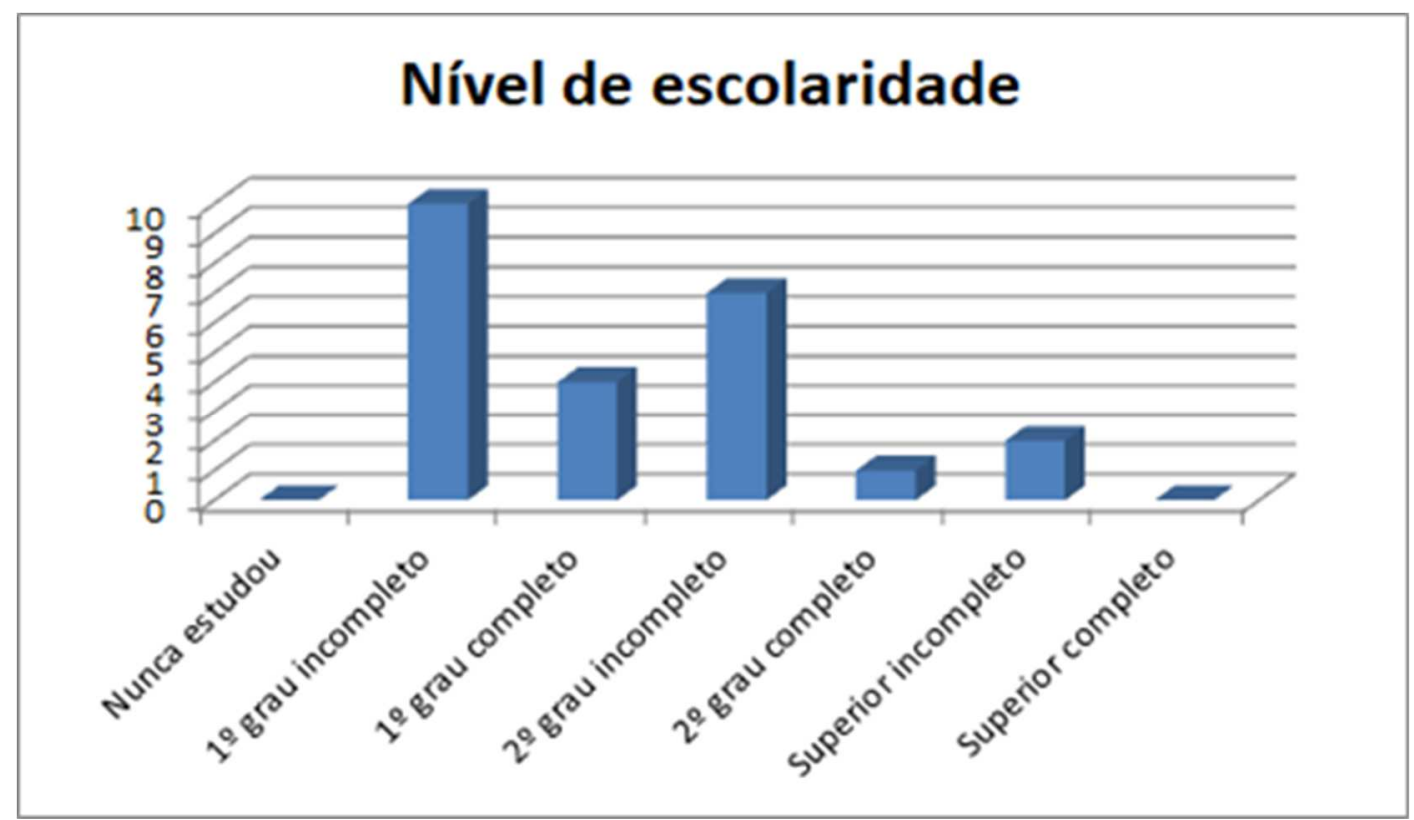

Figura 7. Nível de escolaridade dos entrevistados na Comunidade Rolim de Moura do Guaporé. Fonte: os autores (banco de dados da pesquisa, novembro de 2018).

Os principais pontos levantados pelos moradores da comunidade foram a preocupação com uso dos recursos naturais, a falta de comunicação devido o isolamento do território, bem como a ausência de gestão na comunidade intervindo diante dos principais conflitos sociais e ambientais. O acúmulo de lixo, pesca desordenada, poluição do ar, da água, falta de saneamento dentre outras, nos levam a perceber que são impactos que poderão acarretar danos irreversíveis, visto que a população utiliza os recursos naturais como principal meio para sobreviver.

Devido sua localização, nos limites de um parque estadual e dentro da região amazônica, detentora da maior biodiversidade e concentração de importantes corpos hídricos no território brasileiro, Rolim de Moura do Guaporé é uma área muito visada ambientalmente. Sua população tem consciência da importância do uso sustentável dos recursos naturais e explicitam isso em debates e entrevistas. Com a aplicação de uma oficina sobre a Agenda 2030 com os alunos, ficou evidente que o tema sustentabilidade é trabalhado no ambiente escolar. Estes demonstraram uma grande preocupação com uso dos recursos naturais em decorrência do modo de vida que ali prevalece.

Apesar do reduzido número populacional, em consonância da necessidade da preservação dos recursos naturais para o uso e sobrevivência da comunidade local, está o desenvolvimento de diversas atividades econômicas no território fluvial de Rolim de Moura 
do Guaporé, que impulsionam a ocorrência de impactos diretos e indiretos na área em questão. O uso e ocupação do solo, por meio das construções e propagação de atividades como agricultura e pecuária, geram impactos diversos para a comunidade, acarretando problemas como contaminação hídrica, desmatamento e desgaste do solo. O nível de escolaridade da população ainda é insuficiente diante dos padrões comuns, porém, esta apresenta saberes empíricos e demonstram efetividade quanto às discussões de sustentabilidade. Portanto, com base nos relatos da comunidade e observações in loco, compreende que, apesar de sua localização isolada, da falta de comunicação e fiscalização ambiental, Rolim de Moura do Guaporé possui uma população muito ativa diante da necessidade de preservação dos recursos naturais existentes, visto que estes dão subsídios às atividades de uma comunidade tradicional para o seu próprio sustento e sobrevivência.

\subsection{Ecossistema, cultura e economia}

Ao analisar a comunidade de Rolim de Moura do Guaporé, não pode ser descartadas todas as características ambientais interligadas, ao setor social e econômico para compreender os indicadores, e quais fatores estão exercendo a Força Motriz "Pressão". Para entender essa relação a Figura 8 apresenta a matriz PEIR dos indicadores de sustentabilidade aplicados ao Ecossistema, Cultura e Economia.

O distrito de Rolim de Moura do Guaporé é um dos destinos turísticos mais procurados do estado de Rondônia, devido à pesca, proporcionado pelo tão famoso Rio Guaporé e a diversidade ictiológica da região. A atividade econômica mais atuante na comunidade ocorre por meio do turismo da pesca, com sazonalidade turística de 15 de março a 15 de novembro. Isso gera um impulso na economia da comunidade, que possui pousadas, guia de pesca (piloteiro), cozinheiras, mercearia, como atividades ligadas ao turismo da pesca. Mas esse local vêm sofrendo impactos ambientais ocasionados pelo turismo desordenado recorrente. Um dos pontos negativos enfrentado pela comunidade por meio do turismo é a degradação ambiental do ecossistema aquático e terrestre. 


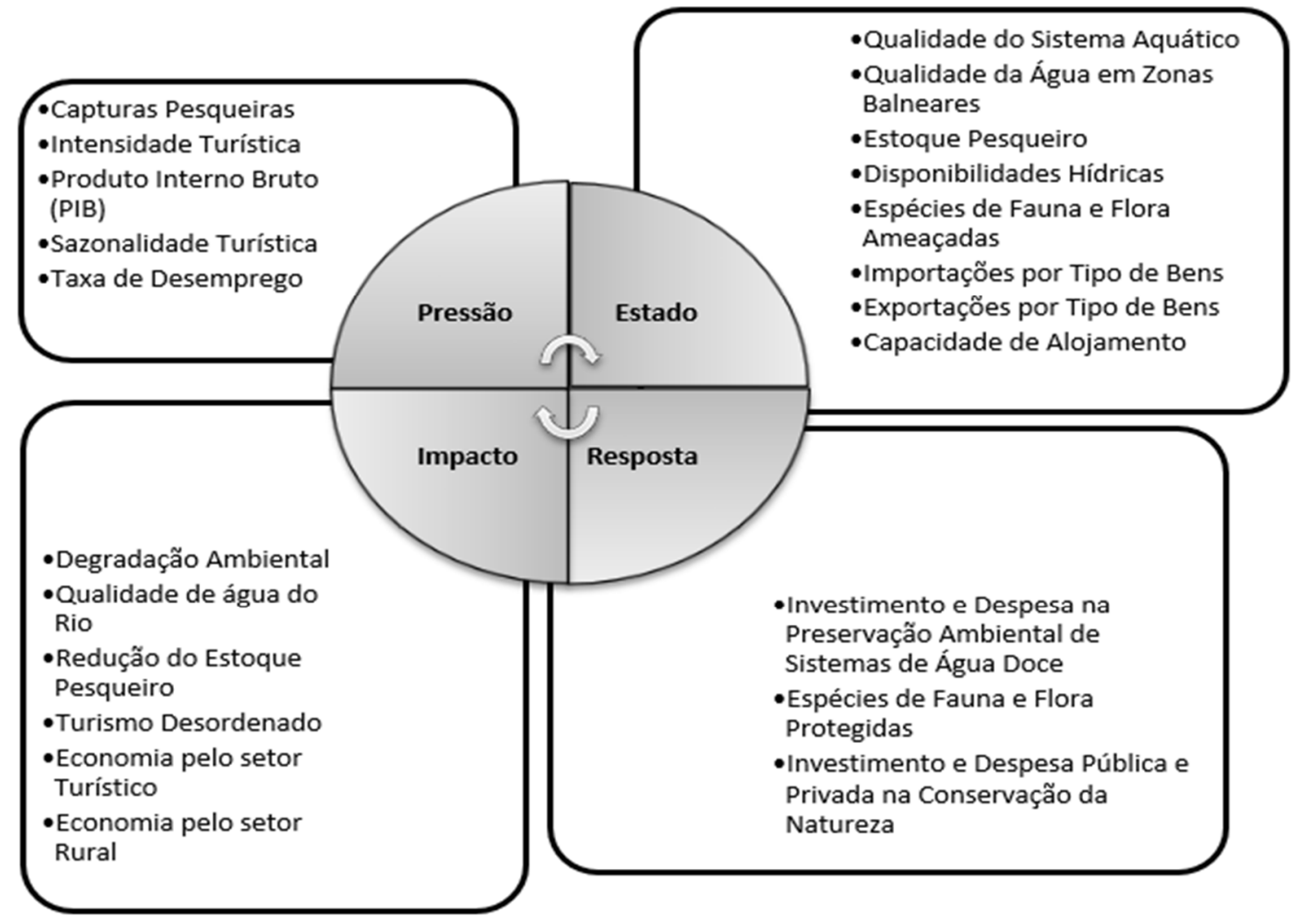

Figura 8. Matriz PEIR de indicadores de sustentabilidade aplicados ao Ecossistema, Cultura e Economia. Fonte: Organizado pelos autores a partir da pesquisa in loco e diretrizes de indicadores da OCDE (2000).

É importante ressaltar que o turismo está entre as quatro principais atividades econômicas do mundo e, hoje, apresenta os mais elevados índices de crescimento em nível global (Oliveira, 2007). Em Rondônia o ecoturismo e o turismo de negócios são importantes na economia do estado. A região ecológica do Vale do Guaporé, onde localiza-se a comunidade, é o quinto destino nacional da pesca esportiva, e o segundo pólo turístico no estado (RONDÔNIA, 2017).

Não somente a economia da comunidade está ligada aos rios, mas também, um conjunto de elementos básicos, de alimentação, cultura, conhecimentos, relacionado ao uso dos recursos naturais. Desse modo, o estado que o meio ambiente se encontra, como a qualidade da água dos rios, a qualidade e disponibilidade do estoque pesqueiro, representa a energia do espaço cultural e econômico da comunidade.

Com a aplicação do questionário foi possível observar, pela visão dos moradores, a qualidade da água, disponibilidade hídrica dos rios e qual o estado da área que vivem. Quando questionados da importância da qualidade do rio, os resultados vão além dos 
números, diz respeito à importância ao local que estão inseridos. Mais de $90 \%$ dos entrevistados afirmam se preocupar com a qualidade do rio, visto que a qualidade do meio ambiente está ligada a qualidade de vida para a comunidade.

Como indicador de estado da qualidade do rio, foi mensurada na entrevista a qualidade do Rio Mequéns Tabela 1.

\begin{tabular}{cc}
\hline Características & No \\
\hline Regular & 10 \\
Ótima & 2 \\
Boa & 5 \\
Ruim & 6 \\
Péssima & 3 \\
Não sabe & 3 \\
\hline Total & 29 \\
\hline
\end{tabular}

Tabela 1. Característica da qualidade da água do Rio Mequéns. Fonte: Os autores (banco de dados da pesquisa, novembro de 2018).

Destacamos a fala de um morador: "Até uns 15 anos atrás usava água do rio pra tudo atualmente é regular", ao analisar tal posicionamento, percebemos que a degradação ambiental está afetando o modo de vida da população local, e que a qualidade hídrica tem papel importante para comunidade.

Nas análises dos indicadores é evidente a importância e conservação da fauna aquática e a flora em uma comunidade conectada à água. Na oficina de diálogos e nas entrevistas, os moradores pontuaram quais impactos estão ocorrendo no cenário hídrico da ilha, como o desaparecimento de espécies de peixes, redução da captura dos peixes para alimentação, assoreamento das margens dos rios pelo desmatamento, aumento dos bancos de areias no rio, pesca predatória e descarte de lixo no rio gerados pelos turistas. Na visão da 
comunidade, a redução do estoque pesqueiro é um indicador da má gestão turística e tais impactos alteram a cultura da comunidade.

Para a comunidade, os responsáveis para mediar e contornar a problemática ambiental ocasionada pelo turismo desordenado é o Poder Público. Esses impactos ao meio ambiente são resultados da ineficiência da gestão pública e fiscalização das autoridades locais. Na ilha há um quartel local da Polícia Militar Ambiental, onde o mesmo encontra-se abandonado e desativado. Acreditam eles, que a implantação de leis e fiscalização no turismo, juntamente com educação ambiental minimize os impactos na ilha.

Os moradores, destacam que a economia do turismo é importante, mas entendem que regras sejam estabelecidas na finalidade de promover uma convivência harmoniosa da comunidade, turismo e o meio ambiente. Corroborando com essa ideia, Oliveira et al.; (2008) destaca que o turismo não ordenado compromete a qualidade ambiental e paisagística, alterando a manutenção dos ecossistemas e prejudicando a própria atividade turística, que tem como alvo atrativo as áreas conservadas e a biodiversidade.

Outro aspecto importante no contexto econômico do turismo é a especulação imobiliária. Seja em grandes cidades litorâneas, ou em pequenas comunidades amazônicas, respondem de acordo com sua capacidade de suporte e infraestrutura local, e movimentam a capitalização. Na comunidade de Rolim de Moura do Guaporé não é diferente, alguns imóveis são construídos apenas para o turismo, as casas de aluguel, que permanecem fechadas fora da temporada de pesca, no período do defeso. Além de pousadas, que hoje, somam sete (7) na comunidade para receber os turistas. As pousadas mobilizam a oferta de bens, como itens alimentícios, bebidas, mas a comunidade não responde com produção local, e os itens são importados do município de Alta Floresta d'Oeste. As pousadas ainda contribuem na geração de emprego informal, através de diárias, oportunidade de renda para as mulheres da comunidade, com serviços de cozinheiras e serviços gerais, para atender a demanda da alta temporada turística.

Por não ter postos de empregos formais na comunidade, o turismo também proporciona os trabalhos autônomos, os moradores oferecem o serviço de guia turístico chamado popularmente de piloteiro. Ligado diretamente à pesca, esse serviço é restrito aos homens, que usam seus conhecimentos do rio para pilotar as embarcações dos turistas guiando-os 
aos pontos mais favoráveis e susceptíveis a pesca, sendo a oferta desse serviço importante fonte de renda na comunidade.

Atualmente, em Rolim de Moura do Guaporé, além do turismo, outra atividade econômica, é a criação de gado na área rural. De acordo com a agência do IDARON de Alta Floresta D'oeste consta cadastrada total de 69 propriedades rurais, dessas, 47 atendidas com criação de rebanho bovino, um total de 5.149 cabeças de gado de corte declaradas no ano de 2018 . Essa atividade é movimentada pelo arrendamento de terras rurais para atividade pecuária, fazendeiros de outros municípios alugam as terras na comunidade para a produção de gado. Esse cenário econômico para uma comunidade de território fluvial não é benéfico ao meio ambiente, a criação de gado em outros estudos mostram os prejuízos ambientais, na qualidade do solo, aumento do desmatamento para área de pastagem, alteração da qualidade dos corpos hídricos pela dessedentação animal, além de alterar os aspectos histórico cultural de um território colonizado por quilombolas, indígenas e ribeirinhos, que têm suas atividades relacionada ao extrativismo, a pesca e não da atividade zootécnica.

A produção rural na comunidade também tem destaque no cultivo de Urucum (Bixa orellana), corante natural conhecido comercialmente como colorau. O uso da semente de urucum em comunidades tradicionais, sobretudo pelos povos indígenas brasileiros é tão antigo quanto suas culturas. Os índios usam a semente como pigmento para proteção contra insetos e queimaduras por exposição ao sol (Morais et al. 2005). Anos atrás o urucum era encontrado nas florestas e atualmente o seu cultivo faz parte da produção econômica das pequenas cidades e comunidades no estado.

Segundo dados da Entidade Autárquica de Assistência Técnica e Extensão Rural do estado de Rondônia (EMATER), o território do Vale do Guaporé, onde está inserida a comunidade é o novo setor produtivo do urucum, sendo que a área plantada no ano de 2018 chegou a 5.500 hectares (EMATER, 2018). No distrito de Rolim de Moura do Guaporé o cultivo da semente de urucum tem chamado atenção como alternativa de negócio e economia para a comunidade. Sua produção em 2018 foi aproximadamente de 80 toneladas de acordo com Secretaria de Agricultura Municipal de Alta Floresta d'Oeste. Essa opção econômica na comunidade, resgata a cultura dos povos tradicionais, juntamente aos conhecimentos empíricos, proporcionando fonte de renda local. 
As relações socioambientais da comunidade diante do tríplice ecossistema, cultura e economia estão associados ao uso dos recursos naturais, fazendo uso dos conhecimentos empíricos culturais para promover a economia local, no entanto enfrentam problemáticas ambientais, como redução do estoque pesqueiro, qualidade da água dos rios, ocasionado pela falta de políticas públicas e ações que promovam o equilíbrio entre a preservação ambiental e cultural deste território.

\subsection{Saneamento básico e resíduos sólidos}

Em relação às questões ambientais, na Figura 9 traz a matriz PEIR dos indicadores, utilizados para a análise do saneamento básico e resíduos sólidos, e principais impactos que têm ocorrido no meio ambiente da comunidade.

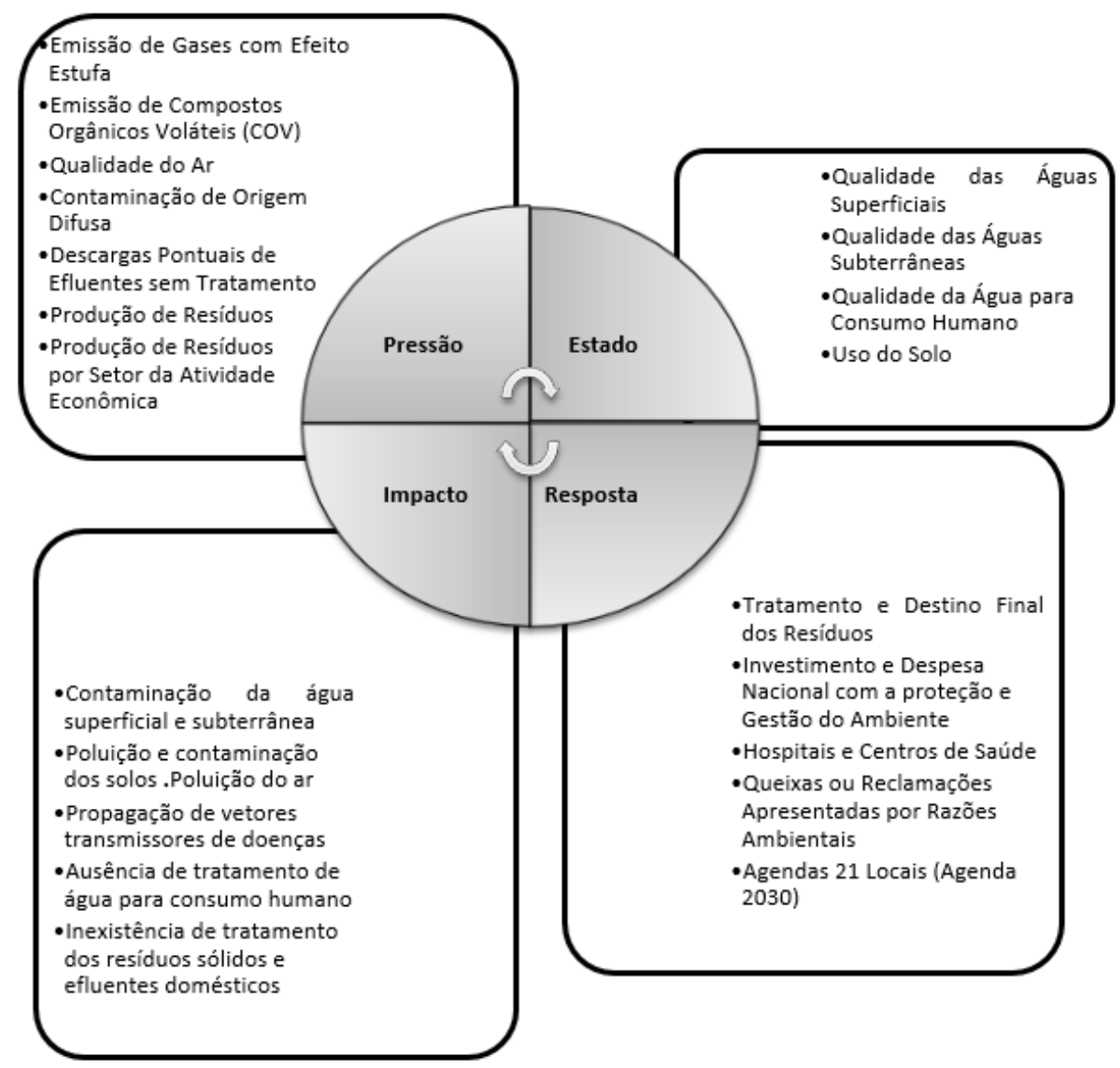

Figura 9. Matriz PEIR de indicadores de sustentabilidade aplicados ao Saneamento Básico e Resíduos Sólidos. Fonte: Organizado pelos autores a partir da pesquisa in loco e diretrizes de indicadores da OCDE (2000). 
Um dos problemas ambientais e sociais mais graves enfrentados por essa comunidade, refere-se ao tratamento e à destinação final dos resíduos sólidos gerados na ilha, com destaque para o período de alta temporada de pesca, com atração de grande quantidade de turistas, que descartam elevada quantidade de lixo como latas, garrafas, copos, sacos plásticos, dentre outros.

Ao longo dos anos essa situação está sendo agravada pelo fato de não haver destinação apropriada dos resíduos sólidos na localidade. Ressalta-se que a questão dos resíduos sólidos é um problema global, uma vez que advém de modelos de consumo insustentáveis. Outro ponto a ser levado em consideração é o grave problema da gestão desses resíduos produzidos, no caso da ilha em estudo, é realizado o descarte final em um lixão irregular a céu aberto.

Outra situação crítica observada na comunidade é a ausência da separação seletiva dos resíduos, muitos desses podem ser reciclados ou reaproveitados, como as latinhas, garrafas de vidro e plásticos, dentre outros (Figura 10G). Na comunidade existia uma cooperativa de reciclagem, porém não estava em funcionamento, uma desvantagem para os moradores, pois com a cooperativa em funcionamento reduziria a quantidade de resíduos que descartado no lixão, além do retorno financeiro para a cooperativa das vendas desses materiais. Um agravante é o fato de ter sido encontrado no lixão resíduos da Unidade Básica de Saúde (UBS) os lixos hospitalares necessitam de coleta e destinação específica, devendo ser incinerados, no entanto estão sendo descartados irregularmente no lixão da comunidade (Figura 10). 

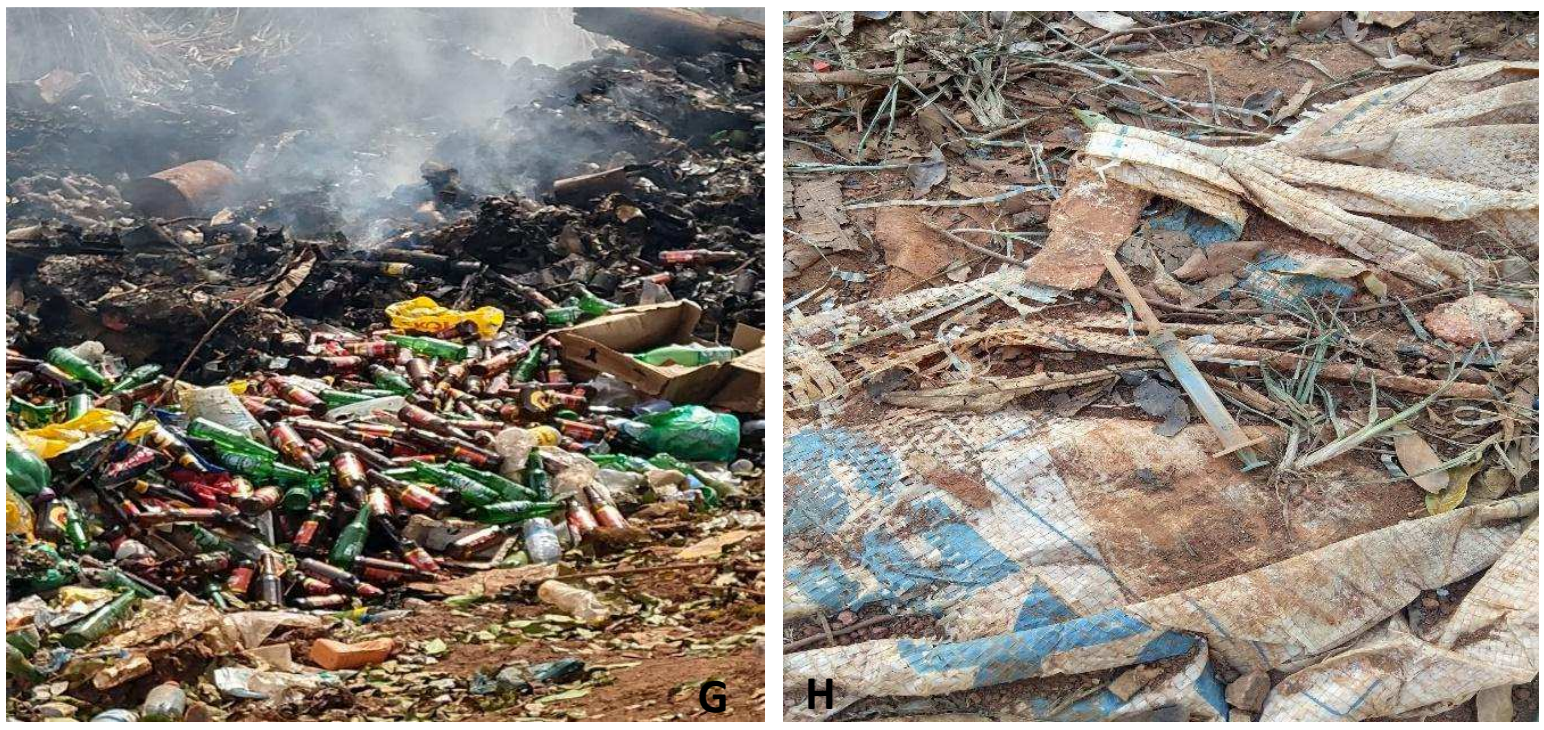

Figura 10. G) Resíduos recicláveis sem separação no lixão. H) Resíduos hospitalar encontrado no lixão. Fonte: Os autores (banco de dados da pesquisa, novembro de 2018).

De acordo com os entrevistados, a Prefeitura Municipal de Alta Floresta do Oeste realiza coleta de lixo nas residências uma vez por semana, depois encaminhados para o lixão, além da inexistência de aterro sanitário na ilha, há também a ausência de controles operacionais ou de qualquer outra forma de tratamento desses resíduos. É indubitável afirmar a necessidade urgente da tomada de medidas de controle, pois ocasionam impactos de contaminação do solo, da água e do ar.

Mais um dos agravantes na comunidade é a queima do lixo, devido ao acúmulo diário, a população busca amenizar a situação realizando a queima dos resíduos sólidos no lixão como pôde ser visto na figura 10G, liberando substâncias prejudiciais ao meio ambiente e a saúde humana.

Conforme apresentado essa disposição inadequada dos resíduos sólidos, têm provocado impactos socioambientais, destacando-se: a contaminação das águas superficiais e subterrâneas, a deterioração do solo; o reforço para a poluição do ar e a propagação de vetores, como moscas, baratas, ratos, dentre outros, que causam a disseminação de doenças. Com a decomposição do lixo, também causa mau cheiro e, devido aos processos de degradação da matéria orgânica existente, há geração de líquido escuro, conhecido como chorume, este altamente poluente. 
A falta de acesso a rede de saneamento básico é indicador importante da pressão exercida no meio ambiente, e à população. A comunidade não possui rede de distribuição de água, utilizando a água de poços nas suas residências para seu consumo, sem processo de tratamento ou desinfecção, assim a população fica exposta a adquirir várias doenças de veiculação hídrica. Associado a isso, existe mais um fator que torna a situação ainda mais preocupante, a ilha não possui rede de coleta e tratamento de esgoto. De acordo com os entrevistados, todos possuem em suas residências fossas negras que estão próximas aos poços, dessa forma há uma grande possibilidade de contaminação do lençol freático e consequentemente da água dos poços consumida.

Diante das pressões que Rolim de Moura do Guaporé tem enfrentado de ordens social, econômica, ambiental e política, o estado do meio ambiente, e os impactos ocasionados, faz-se necessário que o poder público, juntamente com a comunidade se empenhem na formulação e implementação de projetos e planos para mitigação desses impactos e para melhoria da qualidade de vida da comunidade, enfatizando que o gerenciamento dos resíduos sólidos é algo que precisa ser sanado e que a população deverá se entender da importância quanto aos padrões de consumo e principalmente em relação ao reaproveitamento dos materiais que podem ser reciclados. Assim, a educação ambiental aliada às políticas públicas, seja o ponto de partida na de redução e destinação ambientalmente correta dos resíduos sólidos.

\section{Considerações finais}

A construção da matriz PEIR correlacionada com as diretrizes de identificação da OCDE, comumente empregada para áreas de grande visibilidade, neste estudo, teve papel fundamental para uma análise quali-quantitativa da área estudada, apresentando-se como um pequeno território fluvial com baixa população absoluta, porém com impactos inerentes à demais áreas da região amazônica. Demonstrando a relevância de sua aplicabilidade em escalas micros a partir da percepção dos envolvidos diretamente na comunidade.

A identificação de indicadores a partir do diálogo com a comunidade e aplicação de questionário, evidenciaram 63 indicadores distribuídos em três eixos temáticos (Figuras 5, 8 
e 9) trazendo à tona as causas, consequências e como a comunidade local se vê impactada por essa dinâmica metabólica de apropriação do espaço.

Os indicadores demonstram que a gestão de recursos dessa comunidade pode iniciar por questionamentos sobre a qualidade e quantidade de recursos hídricos, porém não se fecha nesta, amplia-se para o desmatamento, auxilio de proteção, a ausência de informação e tecnologia, o acesso à energia e a água tratada, sua mobilidade e em especial o direito a ter voz, tornando evidente que somente é possível nesta comunidade a gestão integrada de questões culturais, econômicas, sociais e ambientais.

Também se faz necessário o suporte técnico para mediar decisões tomadas pela comunidade, e empoderando sua participação, oportunizando melhor eficácia tanto de recursos, quanto dos resultados esperados, tomemos como exemplo a problemática do destino dos resíduos sólidos gerado pelo turismo e pela própria comunidade.

O uso dos recursos naturais no contexto da vivência da Comunidade de Rolim de Moura do Guaporé, nos mostra o quão importante é o papel da gestão pública, e como estes estão sendo discutidos e repensados pela população, ainda mais em um território com tanta especificidade. Há necessidade de políticas públicas voltadas para comunidades tradicionais que visem a conservação dos recursos naturais e preservação da cultura local. Como apontados neste estudo, a comunidade apresenta problemáticas e questionamentos que poderiam ser facilmente solucionados por uma gestão e por políticas públicas eficientes. Aliado à essas, deve-se ressaltar o papel individual exercido pela população como cidadão que almeja a manutenção dos recursos naturais e a minimização dos possíveis impactos existentes.

Este estudo trouxe a necessidade de estimular novos diálogos envolvendo comunidades tradicionais na Amazônia, sua cultura e saberes gerados pela vivência e conhecimentos empíricos e sua relação com o espaço vivido, constituindo um território de significados únicos que precisam ser considerados em políticas públicas destinada a esses espaços. A utilização dos indicadores de sustentabilidade numa comunidade tradicional, como Rolim de Moura do Guaporé, possibilitou reflexões importantes para a funcionalidade desta e da manutenção de seus recursos naturais. 


\section{Agradecimentos}

O presente trabalho foi realizado com apoio da Coordenação de Aperfeiçoamento de Pessoal Nível Superior - Brasil (CAPES) - Código de Financiamento 001, agradecemos também ao Programa de Mestrado Profissional em Rede Nacional em Gestão e Regulação de Recursos Hídricos - ProfÁgua, Projeto CAPES/ANA AUXPE №. 2717/2015, pelo apoio técnico científico aportado até o momento.

Agradecemos em nome das Lideranças à Comunidade de Rolim de Moura do Guaporé pela recepção e confiança neste estudo.

\section{Referências bibliográficas}

BRASIL, 2007. Ministério da Cultura- PALMARES Fundação Cultural. Certidões Expedidas às Comunidades Remanescentes de Quilombos (CRQs) atualizadas até a Portaria no 146/2017, Publicada no DOU de 24/04/2017.Disponível<http://www.palmares.gov.br/wp-content/uploads/2017/04/CCERTID\%C3\%95ESEXPEDIDAS-\%C3\%80S-COMUNIDADES-REMANESCENTES-DE-QUILOMBOS-25-04-2017.pdf>. Acesso em: 14 de jan. 2019.

CARVALHO, Paulo. G. M. de. e BARCELLOS, Frederico. C., 2010. Mensurando a Sustentabilidade. In. MAY, P. Economia do Meio Ambiente: Teoria e Prática. 3 ed. Rio de Janeiro, Editora Campus, p. 99-132.

EMATER, 2018. Entidade Autárquica de Assistência Técnica e Extensão Rural do Estado de Rondônia. Disponível em http://www.emater.ro.gov.br acesso em 10 de jan. 2019.

IBGE, 2019a. Instituto Brasileiro de Geografia e Estatística. Biblioteca catalógo. Disponível em: https://biblioteca.ibge.gov.br/index.php/biblioteca-catalogo. Acesso em: 21 de jan. 2019.

IBGE, 2019b. Instituto Brasileiro de Geografia e Estatística. Bases Cartográficas. Disponível https://mapas.ibge.gov.br/bases-e-referenciais/bases-cartograficas.html. Acesso em: 15 de jan. 2019.

IDARON, 2018. Agência de Defesa Sanitária Agrosilvopastoril do Estado de Rondônia.

MORAIS, Selene. M.; DANTAS, Joana. D. P.; SILVA, Ana. R. A.; MAGALHÃES, Everaldo F., 2005. Plantas medicinais usadas pelos índios Tapebas do Ceará. Revista Brasileira de Farmacognosia Brazilian Journal of Pharmacognosy 15(2): 169-177, Disponível em: doi 10.1590/S0102-695X2005000200017. Acesso em: 05 de jan. 2019. ISSN 0102-695X versão online.

MENDONÇA, Maria S. de; FRANÇA, José F.; OLIVEIRA, Andréia B. de.; PRATA, Ressiliane R.; AÑEZ, Rogério B. da S., 2007. ETNOBOTÂNICA E O SABER TRADICIONAL. In FRAXE, Therezinha de J. P.; PEREIRA, Henrique dos S. And WITKOSKI, Antônio C. Comunidades Ribeirinhas amazônicas: modos de vida e uso dos recursos naturais: EDUA, 2007.

NUNES, Reginaldo O., 2016 - Prospecção etnofarmacológica de plantas medicinais utilizadas pela população remanescente de quilombolas de Rolim de Moura do Guaporé, Rondônia, Brasil - Tese (doutorado) Universidade Federal de Viçosa / Viçosa, MG, 2016.

OCDE, 2000. Organização de Cooperação e Desenvolvimento Econômico. Proposta para um sistema de indicadores de desenvolvimento sustentável. Direção Geral do Ambiente. 228p. p. 15-19. Disponível em PDF https://www.apambiente.pt/_cms/view/page_doc.php?id=308. Acesso em 09 de jan. 2019. 
OCDE, 2002. Organização de Cooperação e Desenvolvimento Econômico. Rumo a um desenvolvimento sustentável Indicadores Ambientais. Cadernos de ReferÊncia Ambiental. V. 9. Centro de Recursos Ambientais. Salvador, Bahia. ISBN 85-88595-08-7.

OLIVEIRA, Elton S., 2007. Impactos socioambientais e econômicos do turismo e as suas repercussões no desenvolvimento local: o caso do Município de Itacaré - Bahia. Revista Internacional de Desenvolvimento Local. Vol. 8, N. 2, p. 193-202. Disponível em doi: 10.1590/S1518-70122007000200006. Acesso em: 10 de jan. De 2019. ISSN 1984-042X versão online.

OLIVEIRA, Ivana S. S.; OLIVEIRA, Danielle C.; GOMES, Laura J.; FERREIRA, Robério A., 2008. Indicadores de sustentabilidade: diretrizes para a gestão do turismo na APA Litoral Sul de Sergipe. Caderno Virtual do Turismo. v. 8, n. 2. p. 46-55. ISSN: 1677-6976.

PNUMA, 2004. Programa das Nações Unidas para o Meio Ambiente. Metodologia para a elaboração de Relatórios GEO Cidades. Manual de Aplicação versão 2. México. Disponível em: <https://edisciplinas.usp.br/pluginfile.php/4218641/mod_resource/content/1/356_Manual_GEO_Cidades_po rt.pdf >. Acesso em: 11 de jan. 2019.

PNUMA 2002. Programa das Nações Unidas para o Meio Ambiente. Projeto Geo Cidades: relatório ambiental urbano integrado - Rio de Janeiro. Rio de Janeiro: PNUMA/MMA/IBAM/ISER/REDEH.

RONDÔNIA, 2017. Superintendência Estadual do Turismo. Notícias. Disponível em: http://www.rondonia.ro.gov.br/rondonia-e-o-primeiro-estado-a-concluir-o-mapa-do-turismo-brasileiro-cincopolos-turisticos-sao-identificados/. Acesso em: 10 de jan. De 2019.

SEDAM, 2009. Secretaria de Estado do desenvolvimento ambiental. Plano de manejo Parque Estadual de Corumbiara. Volume I/IV. disponível em: http://www.sedam.ro.gov.br. Acesso em: 11 de jan. 2019.

SICHE, Raúl; AGOSTINHO, Feni; ORTEGA, Enrique.; ROMEIRO, Ademar., 2007. Índices versus indicadores: precisões conceituais na discussão da sustentabilidade de países. Ambient. soc. [online]. vol.10, n.2, pp.137148. Disponível em: doi:10.1590/S1414-753X2007000200009. Acesso em: 04 jan. 2019. ISSN 1414-753X.

SILVA, Sereide S. F.; SANTOS, Jaqueline G.; CÂNDIDO, Gesinaldo A.; RAMALHO, Ângela M. C., 2012. Indicador de Sustentabilidade Pressão -Estado - Impacto - Resposta no Diagnóstico do Cenário Sócio Ambiental resultante dos Resíduos Sólidos Urbanos em Cuité, PB. Campina Grande: Universidade Federal de Campina Grande, REUNIR - Revista de Administração, Contabilidade e Sustentabilidade - Vol. 2, no 3 - Edição Especial Rio +20, Ago., p.76-93. Disponível em: doi https://doi.org/10.18696/reunir.v2i2.68. Acesso em: 11 de jan de 2019.

VAZ, Cezar. A. B. e SILVEIRA, Geraldo. L., 2014. O modelo PEIR e base SIG no diagnóstico da qualidade ambiental em sub-bacia hidrográfica urbana. RBRH: revista brasileira de recursos hídricos, v. 19, n. 2, p. 281298. Doi: 10.21168/rbrh. v. 19 n. 2. p. 281-298. Acesso em: 15 de jan. 2019.

VEIGA, José. E., 2010. Indicadores de sustentabilidade. Estudos Avançados, IEA:USP, v. 24 n. 68 p. 39-52 São Paulo-SP. Disponível em: http://www.revistas.usp.br/eav/article/view/10465. Acesso em: 10 de jan. 2019. 